\title{
ESTABLISHMENT OF A SYSTEM OF INDICATORS FOR TRANSFORMING THE REGIONAL FARM OF BULGARIA TOWARDS THE BIOECONOMY IN THE CONTEXT OF BIOMASS
}

\author{
D. Toteva, R. Popov, P. Marinov \\ Institute of Agricultural Economics, Sofia, Bulgaria
}

\begin{abstract}
The bioeconomy includes all sectors and systems that rely on biological resources (animals, plants, micro-organisms and biomass, including organic waste), their functions and principles. The use of new technologies in the national economy is a key moment, which will create opportunities for the production of high - quality products from bioeconomy represented by the different types of activities. In the paper presents some of the basic indicators (socio-economic) applicable in the regional economy of the country, based on the principles and factors specific to each region. The transformation of indicators towards the bioeconomy will give greater opportunities for social and economic prosperity in each region of the country according to its specific characteristics.

Biomass is a kind of solar energy conserved in plant and animal organisms. Biomass as a resource includes waste products from animals and human activities. On earth, there is a certain amount of "dead" organic matter that can be used once as a non-renewable resource from organic fuels.
\end{abstract}

Key words: region, indicators, biomass and bioeconomy

\section{INTRODUCTION}

Bioeconomy, as part of the interdisciplinary sciences and industries of modern human society, studies the dynamics in living resource units, using economic models. An attempt is made to apply various methods and methodologies of economics to the environment and ecology pointed at empirical biology. Optimizing the use of resources that a biological system offers without destroying the conditions for its regeneration. Therefore, its ability to stand anthropogenic impact (environmental sustainability) and minimize the adverse effects on it. To explain better the need from bioeconomy and its regulatory frameworks into agriculture and production, we must realize that we live on a planet where resources are limited, a non-renewable resource of economic activities that cannot be replaced to natural resources to deal with the consumption of the material society. (1)

An example is the classic carbon-based fossil fuels, organic material with a high concentration of heat and pressure transformed into oil (type, quality and depth of production) or natural gas. Minerals on earth, fossil fuels, coals and groundwaters are considered as nonrenewable resources, although their individual elements are always recovered or preserved in minimal quantities.

\section{METHODS}

The bioeconomy includes all sectors and systems of economy at regional and national levels that rely on biological resources (animals, plants, micro-organisms and biomass, including organic waste), their functions and principles. It includes and connects - land and sea ecosystems, all subsectors of production that use and produce biological resources (agriculture, forestry, fisheries and aquaculture), as well as all economic, and industrial sectors that use biological resources and processes for the production of food, feed, organic products, energy and services. This stimulates the renewal of our industries, the modernization of our primary production systems.

According to (Chernov, 1994) in his book: „Prospects for the creation of self-reproducing automatic systems (PAS) ", defines the bioeconomy as... ,production based only on 


\section{TOTEVA D., et al.}

reproducible machinery systems". He writes the following: "The balanced growth of this big, ever-expanding system (the global economy) becomes more difficult every year, which will soon or later lead to its standstill in the developed world countries. In order to prevent this, we must implement new approaches in the organization of material production. One of these decisions can be given to us by wildlife, which in some sense can be seen as a kind of production system. In his subsequent reflections, A. Chernov promoted the idea of introducing the bioeconomy as an alternative to overproduction in the world or to recycle completely the waste product. (2)

Here is the place to make the "small" difference between the bioeconomy and the circular economy, the first often confused with the second. The bioeconomy focuses on the production and use of renewable bioecological resources and their transformation into valueadded products such as food, feed, bio-energy, biological materials and others according to available technology. The circular economy is an alternative to the traditional economy. In the circular economy we keep resources in use as long as possible. We extract the maximum value from the resources during the use and recycle when it is possible.

According to (Mihailova, 2019) ... "the research in the field of bioeconomy is still at the initial stage". This branch of the circular economy should be developed as a separate discipline, not simply as an economic framework for defining / enriching the concept of sustainable development. (7)

According to the authors of this material, bioeconomy involves the study of different aspects of the economy (the three economic sectors), while processing resources from waste products from the primary and secondary sectors of the economy.

The bioeconomy contributes to the achievement of the EU and the UN goals for sustainable development, better salaries, job creation, halting the climate change from Paris Agreement in 2015, modernizing and strengthening of the production, restoration of ecosystems, the neutrality of land degradation, reduction of discarded food and transformation of cities into centres of bioeconomic ally balanced development. (3)
The development of the bioeconomy must be based on a regional approach specific to EU countries. It is related to the European classification NUTS (Classification of territorial units for statistical purposes) and within the meaning of the law in Bulgaria from 2008, regions are formed on the basis of their geographical location and population. Based on this classification, the country is divided into three levels: NUTS 1 covers the two territorial zones of North and South-East Bulgaria and South-West and South-Central Bulgaria; NUTS 2 covers the six statistical regions (North-West, North-Central, NorthEast, South-West, South-Central and SouthEast); NUST 3 are 28 administrative territorial areas. At the local level, LAU1 are 264 municipalities, 232 of which belong to rural areas from 31.12.2015. (5)

\section{RESULTS}

Production related to the bioeconomy and the supply of raw materials must be located in such a way that the connection between them to be optimal, on the one hand, the production produced to be supplied unimpeded to the market network, on the other hand, the transport of raw materials does not load the transport arteries and lastly, moving of the workforce to production have to be quick and convenient. Cities should become important centers of bioeconomy (center-periphery). Circular material management and recycling (or, when applicable re-refining) of urban waste, including organic waste are of great importance, and not only infrastructure, collection, treatment and recycling (or rerefining), but also efforts to raise public awareness. (6)

The Bioeconomy Development Strategy is based on 3 pillars: 1) investment in research; 2) developing markets and developing competitiveness with bio-products and consumption of bio-products; 3) enhanced policy coordination and involvement of all stakeholders. Based on the three pillars that create the condition for the development of the bioeconomy as a scientific activity, on the one hand, and on the other hand organization of production processes, we propose a several indicators that can be transformed depending on the types of production ( the process is open to new ideas), raw material base and location:

1) Bioeconomy development policy The bioeconomy interacts in the coherence between policy, science and economic sectors 
related to the production and consumption of bioproducts. It is important to encourage producers, processors, research teams, users, policymakers. The bioeconomy research and innovation process is the basis for real success.

2) Promoting and protecting the environment - This is the basis on which the bioeconomy must be built and developed as a scientific justification, philosophy and production activity related to the processing and use of environmentally friendly raw materials in urban areas or outside.

3) Investing in the bioeconomy should be linked to the introduction of new technologies and capacities in the economic sectors directly related to the processes of the bioeconomy. The input of new technological facilities will allow the complete processing of resources and zero pollution of the environment.

4) Labour market focused on the bioeconomy - job creation in a new area at national level always has priorities and support from the state institutions. New jobs engage the population, raise the standard and stabilize socio-economic policies at the region level. On the other hand for employers are created the opportunity to form an investment policy that creates the conditions for job creation.

5) Development of individual regional bioeconomy strategies - for the development of new sectors of the bioeconomy requires the development of National and regional programs that meet the relevant needs and requirements for the respective area. Each strategy or program must be specific to each territory and to be protected by investment and manpower, and last but not least, environmental protection.

6) Investments in research - In the process of building and development of the bioeconomy in the country and at the level of the region, the cooperation with research centers in the country and abroad should be actively implemented and maintained. The cooperation with the Universities of Food Technologies, which have modern technology, equipment and methods for the development of innovative products in the food field, their testing and implementation is also important. The cooperation with scientific centers, organizations participating in the BioSTEP project, the Bulgarian Chamber of Commerce, business organizations is very important. In this way, it will be possible to follow the latest scienctific developments in innovative technologies and to introduce highly efficient technologies for the production and marketing of bio-products and essential bio-products. (4)

By its nature, the biomass is one of the most important accumulators of solar energy, its total volume being determined by its ability to convert through photosynthesis in the plant world. The energy of biomass from all organic materials is transformation into some form of human-known energy. Therefore, from the renewable energy sources point of view, biomass refers to all organic products derived from plants and waste. In contrast, fresh biomass is constantly recovered, it is a renewable energy source. At present, its use is associated with the application of significantly more sophisticated technological solutions than conventional fuels. Therefore, conventional resources are used much more fully than nonconventional ones. There are a variety of forms of biomass that can be used for energy purposes. Such are wood and wood waste; energy-saturated crops; agricultural waste; straw, corn stalks, liquid waste from animals, etc .; industrial waste; sewage sludge. (8)

Biogas in nature reacts with oxygen, has a burning process, but with a very low temperature difference from the environment. Therefore, biomass is considered to be a renewable energy source that has virtually no environmental pollution, i.e. it is green energy. In contrast, energy from fossil fuels provides significant additional effects that simultaneously degrade the natural environment. The closest and most known to man biomass used for energy purposes is wood. Another well-known form of biomass is the various agricultural residues and forestry, waste paper and cardboard in urban waste, energy crops, methane from landfills and wastewater. (9)

In the article the possibilities of using different types of biomass for energy production and the establishment of a system of indicators for the transformation of regional farms to bioeconomy are examined. Types of biomass and its use as an energy source. The types of biomass can be:

- Bioenergy resources

An important resource is the specific crop perennials that can supply enough in volume resources, such as grass, bamboo, sweet sorghum and others. Crops with bioenergy resources also include tree species such as 
maple, poplar, ash, willow and others. Another important part of such resources are corn starch and oil, soybean oil and soybean, wheat starch and other vegetable oils. In addition, bioenergy resources exist in sea and freshwater environment, such as algae and microflora, and others that can be used in bioprocesses.

- Agricultural Crops

Crop residues include mostly stems and leaves - for example, straw in wheat harvest, corn stems, etc. There are also residues of biomass in the forestry and woodworking industries for example, not enough harvested biomass from felling, thinning of diseased trees, and others.

\section{- Natural oilseeds}

There are fat-rich crops in nature that can be used for fuel after pressing. Due to the price differences of the starting products, vegetable fuels can hardly find an application. Biodiesel as a fuel derived from vegetable oils is more widely used.

\section{- Household and animal waste}

Non-recoverable household waste has significant resources. They contain a portion of organic plant material, which is itself a resource for rapidly renewable energy. Such is also waste paper, wood and garden waste. In addition, the accumulation and treatment of wood lead to sawdust, bark and leaves. Animal waste is the result of the operation of farms, slaughterhouses and meat processors, which result in the emergence of organic materials and which can be used as an energy source.

Problems with biomass utilization:

1) Investments in biomass utilization require an assessment of how much the raw material costs, the purchase price of the electricity produced and the fixed costs associated with the reliability of the installation;

2) First, investors in waste materials and steam and electricity production face high and often uncertain starting materials prices. Despite the advanced technologies of modern installations for the provision of raw materials and transportation, the installation can have many costs, making the venture unprofitable;

3) The second problem is the relatively common problems with electricity financing. Electricity is bought at different prices depending on what it is being produced and what is the political view on the problem. Some inconsistency in this regard may lead to irrational investment decisions;

4) The third problem concerns the reliability of the electricity or heat production. Often the costs of maintenance are much higher than in the project.

The benefits of biomass can be summarized as follows:

1) Organic fuels are a major obstacle to the more sustainable development of humanity. From this point of view, biomass and its energy are a possible solution;

2) Biomass is significantly more evenly distributed around the world and therefore it gives the possibility to reduce dependence on oil import;

3) The production of biomass and the use of agricultural waste for biomass will stimulate rural development in the agriculture, forestry and related industries;

4) Biomass technologies are more consistent with environmental quality than conventional energy technologies;

5) Biotechnology alternatives would help reduce air pollutant emissions from organic fuels. (10)

Is biofuel production economically viable? Increased demand for biofuels is closely linked to population nutrition. Currently, a significant amount of fuel is provided through biomass, but if this continues, a sharp increase in agricultural prices can be expected. The problem is clear and no significant increase in the production of biofuels can be expected in the medium to long term. However, in the coming years, it can be expected that the demand for this type of fuel will continue and will cause even more demand for sugar, oilseeds, maize, etc. for energy needs. This will lead to increase in agricultural commodity prices and therefore a difficulty in feeding the population. In recent years, the production of oil from pins depends on the advancement of mining technologies has gained considerable size. This added a new source of fuel for energy purposes and therefore a new competitor for biofuels. Shell oil and gas producers may have a good position in the immediate future.

Will biofuels continue to be produced? Almost all countries have adopted rules and laws that provide tax rebates for the sale of ethanol to gasoline and biodiesel for diesel engines. We 
can suppose that if developed countries give up their subsidies and accept market opening, all producers, both poor and rich, can benefit. Biofuels markets for developing countries can contribute to rural areas' development. Rising biofuels prices and the associated increase in agricultural prices can give some developing countries a chance.

\section{CONCLUSION}

Bioeconomy as a science and production can be applied both at national and regional levels. The indicators presented may be supplemented or modified depending on their theoretical or practical application. Investment and cooperation with scientific organizations are essential for the development of the bioeconomy, the introduction of new technologies in combination with scientific capacity will create a symbiosis between theory and practice. Organic fuels are a major obstacle to the more sustainable development of humanity. From this point of view, biomass and its energy are a possible solution. Biomass is significantly more evenly distributed around the world and therefore it gives the possibility to reduce dependence on oil import. The production of biomass and the use of agricultural waste for biomass will stimulate rural development in the agriculture, forestry and related industries. Biomass technologies are more consistent with environmental quality than conventional energy technologies. Biotechnology alternatives would help reduce air pollutant emissions from organic fuels. The development of agriculture and the growing role of the bioeconomy as an economic and scientific potential can be an engine of growth and help overcome malnutrition and poverty. The problem is most important for developing countries, because most of their population spends half of their incomes for food. Moreover, the strong growth of biocultures does not completely address the threat to the environment - it does not necessarily lead to an automatic reduction of greenhouse gases into the atmosphere. Almost everyone notes that land use changes have the biggest impact on emissions. The changes related to deforestation for the needs of developing agriculture are an
TOTEVA D., et al.

obstacle for land quality and biodiversity of greenhouse gases.

\section{ACKNOWLEDGEMENTS}

We wish to thank the National Scientific Program "Healthy foods for a strong bioeconomy and quality of life" to work Package 4.1. Importance of bio-economy for regional development, agro-food chains and quality of life. For publication of the scientific material.

\section{REFERENCES}

1. Bashev, H., Sustainability of agricultural farms in Bulgaria, Avangard Prima, Sofij 2016, ISBN: 978-619-160-738-9.

2. Chernov,A., , Prospects for the creation of self-reproducing automatic systems (PAS), 1994, chernovau@ list.ru.

3. Energy Economics Group - The project INVERT 2005, financed by EC, www.invert.at

4. European Commission Energy for the future: renewable sources of energy, http://ec.europa.eu/energy/res/index_en.htm

5. Marinov, P., Rural Infrastructures of the South Central District, Plovdiv, 2017, bulge Fast Print Books, ISBN: 978-6197312-73-7.

6. Markov N., Spatial analysis of trade activity using geographic information systems, Economic Thought Journal, 2019, p. 111, ISSN 0013-2993.

7. Mihailova, M., Development of circular economy and bioeconomy in Bulgaria, National Scientific Conference "75 Years of the Union of Scientists in Bulgaria - for the benefit of science and education", 2628.09. 2019.

8. Ministry of Economy and Energy, 2005 National long-term program to promote the use of renewable energy sources 20052015, http://www.eneffect.bg/eeinfocenters/Legislation/NDPVEI.pdf

9. Petar Borisov, Dimitre Nikolov, Teodor Radev, Ivan Boevski. ANALYSIS OF MECHANISMS TO SUPPORT THE AGRICULTURAL SECTOR IN THE CREATION OF PUBLIC GOODS. Journal of Bio-based Marketing, 2020, 1(1), 65-72.

10.Project, Strategy for Bioeconomic Development in Stara Zagora. 2017, https://www.biabg.com/uploads/files/event/ 